\title{
Schizophrenia-spectrum patients treated with long-acting injectable risperidone in real-life clinical settings: functional recovery in remitted versus stable, non-remitted patients (the EVeREST prospective observational cohort study)
}

Elisabeth Giraud-Baro ${ }^{1}$, Daniel Dassa ${ }^{2}$, Florent De Vathaire ${ }^{3}$, Ricardo P. Garay ${ }^{4^{*}}$ and Joelle Obeid ${ }^{5}$

\begin{abstract}
Background: Previous studies showed functional improvement in stable patients with schizophrenia treated with risperidone long-acting injection (LAl). We therefore re-investigated functional improvement with risperidone LAl in remitted patients, in comparison with stable patients. The study was conducted in real-life conditions because of the high heterogeneity of the patients' situations.

Method: This was a multi-centre, prospective observational cohort study involving adult schizophrenia-spectrum chronic patients who were previously treated with risperidone LAl for 6 months. Remission was evaluated using the consensus criteria proposed by the Remission in Schizophrenia Working Group (RSWG). The primary endpoint was global functioning (assessed with the Global Assessment of Functioning scale, GAF) after one year of treatment. Social functioning was a secondary outcome.

Results: The analysis included 1490 patients. Attrition rate was $9.1 \%$ at the end of the study. $27.7 \%$ of patients were in remission after one year of risperidone LAI treatment. The mean GAF rating score $(62.5 \pm 1.5)$ was higher than the cut-off previously used to identify patients with satisfactory functioning (60) and significantly higher than the mean GAF score in stable, non-remitted patients $(48.3, p<0.001)$. Social functioning was also high in remitted patients ( $21.0 \pm 3.6$ vs. $17.2 \pm 3.7$ in non-remitted patients, $p<0.001)$.
\end{abstract}

Conclusion: The results clearly show that after one year of treatment with risperidone LAI, RSWG-remitted patients have a high level of global functioning, which is significantly higher than in stable, non-remitted patients. Social functioning was also higher in remitted patients as compared with stable, non-remitted patients.

Keywords: Functioning, Schizophrenia, Social functioning, Risperidone, Risperidone long-acting injection

\footnotetext{
* Correspondence: ricardo.garay@orange.fr

${ }^{4}$ Craven, Villemoisson-sur-Orge, France

Full list of author information is available at the end of the article
} 


\section{Background}

A long-acting injectable (LAI) form of the atypical antipsychotic risperidone was introduced 12 years ago to reduce the risk of partial compliance and adverse outcomes in patients with schizophrenia [1-3]. The symptomatic efficacy of risperidone LAI was evaluated using the consensus criteria proposed by the Remission in Schizophrenia Working Group (RSWG; a state of no greater than low-to-mild intensity in core psychotic symptoms, sustained for a minimum duration of 6 months) [4]. These studies showed higher remission rates with risperidone LAI (21-45 \%) [5-8] as compared with oral antipsychotics (between $6.3 \%$ for risperidone and $12.4 \%$ for olanzapine) [9].

The ultimate goal of treatment in schizophrenia is recovery, i.e., patients regaining functioning and participating in social and vocational opportunities [10]. Previous interventional studies showed functional improvement under risperidone LAI treatment in patients with nonacute, stable schizophrenia or schizoaffective disorder [11-14]. On the other hand, a post-hoc analysis of the StoRMi (Switch To Risperidone Microspheres) interventional trial showed both, global functioning recovery and RSWG-remission in $21 \%$ of patients under risperidone LAI [15]. Finally, the therapeutic benefit of drugs should be re-examined in real-life conditions because of the high heterogeneity of the patients' situations.

Taking all the above elements together, we reinvestigated functional improvement with risperidone LAI in RSWG-remitted patients, in comparison with stable patients. The study was conducted in real-life conditions because of the high heterogeneity of the patients' situations (the EVeREST, EValuation of functioning in REmission after Symptomatic Treatment, study). Although the Global Assessment of Functioning (GAF) scale is widely used to evaluate functioning, we decided to use an additional scale, to evaluate social skills and social roles ("ad hoc" scale shown in Table 1).

\section{Methods}

\section{Study design}

This was a multi-centre, prospective observational cohort study of 1554 adult schizophrenia patients who were initiated to risperidone LAI treatment 5 to 7 months before the beginning of the study (Fig. 1). Data was communicated by 381 French psychiatrists, between July and December 2008. The study was sponsored by Janssen Cilag (Issy les Moulineaux, France). C2R (Paris, France) was in charge of the setting-up of the study and provided access to the TVF database of CEGEDIM (Centre de gestion et de Documentation de l'Information Médicale; Management and documentation centre of medical information, Boulogne-Billancourt, France). STATITEC (Labege, France) was in charge of the statistical analysis.
Table 1 Social Functioning in Schizophrenia scale

\begin{tabular}{|c|c|}
\hline Item & Characteristics \\
\hline \multicolumn{2}{|l|}{ Social skills } \\
\hline $\begin{array}{l}\text { Personal care and } \\
\text { appearance }\end{array}$ & Personal hygiene and clothing \\
\hline Housekeeping & Housework, laundry, shopping (food, etc.) \\
\hline $\begin{array}{l}\text { Familial and social } \\
\text { integration }\end{array}$ & $\begin{array}{l}\text { Relationships necessary to maintain } \\
\text { harmonious integration }\end{array}$ \\
\hline $\begin{array}{l}\text { Information and } \\
\text { execution }\end{array}$ & $\begin{array}{l}\text { Ability to get information and fulfill administrative } \\
\text { and social formalities of everyday life }\end{array}$ \\
\hline \multicolumn{2}{|l|}{ Social roles } \\
\hline $\begin{array}{l}\text { Organizing free } \\
\text { time }\end{array}$ & $\begin{array}{l}\text { Ability to engage in social, creative or recreational } \\
\text { activities (attendance at social groups, foundations, } \\
\text { clubs or groups of mutual aid) }\end{array}$ \\
\hline $\begin{array}{l}\text { Managing } \\
\text { stigmatization }\end{array}$ & $\begin{array}{l}\text { Knowing one's disability, asserting rights, } \\
\text { withstanding criticisms }\end{array}$ \\
\hline Working ${ }^{a}$ & $\begin{array}{l}\text { Ability to project into professional life according } \\
\text { to the degree of disability. Having a job in } \\
\text { a protected or ordinary environment }\end{array}$ \\
\hline
\end{tabular}

Scale. 1: do not do -2 : neglect -3 : do, but with efforts -4 : do without effort ${ }^{a}$ Scale. 1: not applicable - 2: projects of professional life -3 : in training for working rhythms -4 : has a job in a protected or ordinary environment

The study was declared to the CNIL (Commission Nationale de l'Informatique et des Libertés; National Committee of informatics and Freedom) and authorized by the CCTIRS (Comité Consultatif pour le Traitement de l'Information en matière de Recherche dans le domaine de la Santé; Advisory Committee for the Evaluation of Information in the field of Health Research) [16]. Patients were informed about the study by the participant psychiatrists and gave consent to communicate data. The study also agreed with the Helsinki Declaration (1975, revised 1983) (World Medical Association Declaration of Helsinki: http:// www.wma.net/en/30publications/10policies/b3/index.html).

The number of French psychiatrists practicing in a public or private structures for management of psychotic patients, including patients with schizophrenia, was estimated at 5500 [17]. A list of 1500 physicians, balanced and stratified by region, was selected at random by using the TVF database to obtain a representative sample at the national level. This database, which is commonly used by French Health Services, is under the control of the CNIL. The psychiatrists interested in participating were contacted by regular mail to obtain a written agreement to take part in the study and certify their knowledge in safety procedures concerning serious adverse events.

The study included adult patients (18-65 years old) diagnosed as schizophreniform or schizophrenia disorder (DSM-IV criteria) who had been under treatment with risperidone LAI for five to seven months and who had decided to continue treatment (Fig. 1, M-6). To ensure representativeness of the studied population, only the first three consulting patients 


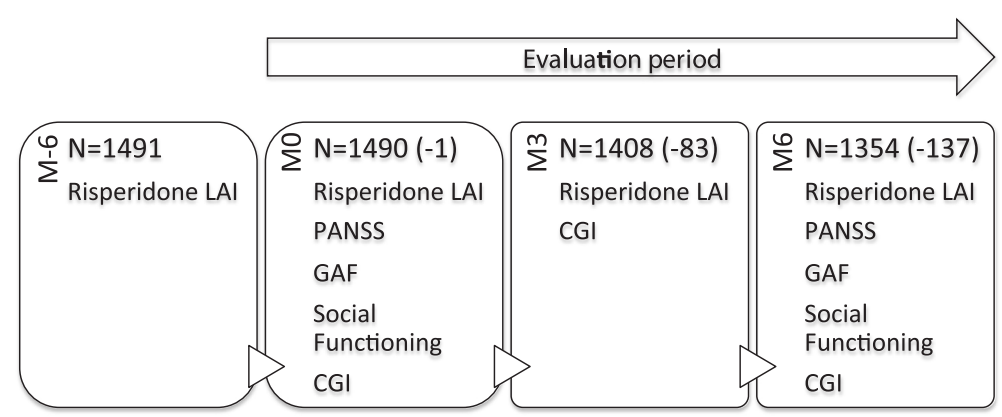

Fig. 1 Clinical study flow diagram. Number of patients is given with dropout numbers in brackets. M-6 (risperidone LAl initiation, 6 months before inclusion), M0 (month 0, first evaluation visit), M3 (month 3, follow-up visit), M6 (month 6, end of study)

were included. The evaluation period was six months and included three visits (Fig. 1): visit 1 (M0, month 0 ; 6 months after risperidone LAI initiation), visit 2 (M3, month 3; 9 months after risperidone LAI initiation), and visit 3 (M6, month 6; at the end of the study, 12 months after the initiation of risperidone LAI treatment).

At visit $1,70.8 \%$ of patients had an adjunctive drug treatment (anxiolytics $57.6 \%$ of patients, hypnotics $41.8 \%$, antidepressants $30 \%$, antiparkinsonians $21.3 \%$ and mood stabilizers $21.0 \%$ ). Moreover, $55.7 \%$ of patients received psychosocial interventions.

\section{Data collection}

The participating psychiatrists collected the following patients' information (in case report forms):

$>$ At M0

$\checkmark$ Demographic aspects

$\checkmark$ History of schizophrenia or schizophreniform disorder

$\checkmark$ Actual clinical and therapeutic aspects, including:

- Treatment follow-up (number of missed injections, date and reason for discontinuation of treatment, if necessary)

- PANSS (positive and negative symptom scale) core of psychotic symptoms

- Functioning, assessed by the Global Assessment of Functioning (GAF) scale and by a Social Functioning in Schizophrenia "ad hoc" scale (Table 1). This latter evaluates social skills (4 items) and social roles (3 items).

- Clinical Global Impression (CGI) - Severity and improvement scales

$>$ At M3 (3 months \pm 15 days)

$\checkmark$ Clinical and therapeutic aspects, including:

- Treatment follow-up (number of missed injections, date and reason for discontinuation of treatment, if necessary)
- Clinical Global Impression - Severity scale (CGI-S)

- Adverse events (AE)

$>$ At M6 (6 months \pm 1 month) or termination of the study

$\checkmark$ Clinical and therapeutic aspects, including:

- Treatment follow-up (number of missed injections, date and reason for discontinuation of treatment, if necessary)

- PANSS core psychotic symptoms

- Functioning, assessed by the GAF scale and by an ad hoc Social Functioning in Schizophrenia scale (Table 1).

- Clinical Global Impression (CGI) - Severity and improvement scales

- $\mathrm{AE}$

\section{Outcome data analysis \\ Primary endpoint}

Global functioning in patients remitted $(N=374)$ and non-remitted $(N=976)$ at M6. Remission was evaluated using the consensus RSWG criteria, i.e.,: a state of no greater than "mild" intensity in core psychotic symptoms, sustained for a minimum duration of six months [4]. As per DSM-IV (see ref. [18]), a score of 60 out of 100 was taken as a cut-off to identify patients with moderate to severe impairment in functioning (GAF score $\leq 60$, representing some mild difficulty in socio-professional activities or satisfactory activity).

Missing data concerning PANSS and/or GAF data at M0 and/or M6 were considered as major deviations to the protocol.

\section{Secondary endpoints}

> Social functioning: evolution, comparison of social functioning between remitted and non-remitted patients at M6

$>$ Social abilities as a function of psychosocial measures

$>$ AE in "real-life" 


\section{Adverse events}

Adverse events (AE) were reported in the case report forms beginning at the inclusion of the study (M0) until one month after the study was finished. AE appearing with a delay that was chronologically consistent with the administration of the product were considered to be related to risperidone LAI treatment when a causal relationship was possible, likely, or very likely:

Possible relation: The AE can also be attributed to a concomitant disease or other medications. Causality cannot be excluded.

> Likely relation: The attribution to a concomitant disease or the other medications does not seem likely, and risperidone LAI treatment discontinuation led to the disappearance of the AE or improved symptoms.

> Very likely relation: The AE cannot be attributed to a concomitant disease or other medication. The time to onset was chronologically very consistent with the administration of risperidone LAI, risperidone LAI treatment discontinuation led to the disappearance of the AE or improved symptoms, and risperidone LAI re-administration led to a recurrence of the same AE symptoms.

\section{Patient population size}

We estimated that an initial sample size of 1500 patients was required to have $\geq 80 \%$ power in detecting a difference in outcome of $\geq 10 \%$ (if the two populations were relatively similar in size and that the smallest comprises $35 \%$ or more of the total survey population).

\section{Statistics}

Statistical comparisons between the two groups of patients were done by using the following tests: MantelHaenszel Chi-2 test for stratified categorical variables, Chi-2 of the homogeneity test for non-stratified categorical variables, and the non-parametric Wilcoxon test for continuous variables. The statistical level of significance was accepted for $p$ values $<0.05$. Values are presented as mean \pm SEM (standard error of the mean).

\section{Results}

The study included 1491 patients at M0 (security safety analysis set). One patient was excluded because of a major protocol deviation (no PANSS or GAF data available from M0 or M6). Of the remaining 1490 patients, $1408(94.5 \%)$ and 1354 (90.9 \%) were seen again at M3 and M6, respectively. The main reason for discontinuation was patients' decision (68.6\%). Follow-up time was $5.6 \pm 1.0$ (mean $\pm \mathrm{SD})$.
Demographic aspects and medical history of the participating patients

Table 2 shows demography and psychiatric history of the patients at M0 and M6. At M0, patients were mostly men $(65.2 \%)$ and their average age was $36.7 \pm 0.3$ years. Most of them were single (69 \% of patients) and without children (72\% of patients). More than half were on disability or sick leave for psychiatric disorders (56\% of patients). More than three-quarters of patients (76.4\%) were

Table 2 Demographic aspects and medical history of the included patients

\begin{tabular}{|c|c|c|}
\hline & Month 0 & Month 6 \\
\hline Number of patients & 1490 & 1354 \\
\hline Age (years) & $36.7 \pm 0.3$ & $36.8 \pm 10.9$ \\
\hline Sex (\% males) & $65.2 \%$ & $64.6 \%$ \\
\hline \multicolumn{3}{|l|}{ Marital status (\% patients) } \\
\hline Married or cohabiting & $17.2 \%$ & $16.9 \%$ \\
\hline Single & $68.9 \%$ & $68.8 \%$ \\
\hline Divorced, widowed, separated & $13.9 \%$ & $14.3 \%$ \\
\hline Patients with children (\% patients) & $27.6 \%$ & $27.8 \%$ \\
\hline \multicolumn{3}{|l|}{ Accommodation (\% patients) } \\
\hline Independent housing & 62.6 & 63.1 \\
\hline Dependent housing & 20.9 & 20.7 \\
\hline Homeless housing & $1.3 \%$ & $1.3 \%$ \\
\hline Hotel & $0.9 \%$ & $1.0 \%$ \\
\hline Institutional center/Foundation & $8.9 \%$ & $8.7 \%$ \\
\hline Retiring home & $0.5 \%$ & $0.6 \%$ \\
\hline Other & $4.8 \%$ & $4.7 \%$ \\
\hline \multicolumn{3}{|l|}{ Current employment status (\% patients) } \\
\hline Employee & $12.2 \%$ & $11.7 \%$ \\
\hline Student or in training & $6.3 \%$ & $5.9 \%$ \\
\hline Help Center for Labor & $7.2 \%$ & $7.3 \%$ \\
\hline Unemployed or retired & $9.6 \%$ & $9.5 \%$ \\
\hline Freelancer & $1.0 \%$ & $1.1 \%$ \\
\hline Disabled or sick leave for psychiatric disorder & $56.4 \%$ & $57.0 \%$ \\
\hline Status unknown & $0.8 \%$ & $0.9 \%$ \\
\hline Other & $6.5 \%$ & $6.5 \%$ \\
\hline \multicolumn{3}{|l|}{ Psychiatric history } \\
\hline \multicolumn{3}{|l|}{ DSM-IV diagnostic (\% patients) } \\
\hline Schizophrenia & $76.4 \%$ & $76.4 \%$ \\
\hline Schizophreniform disorder & $23.6 \%$ & $23.6 \%$ \\
\hline \multicolumn{3}{|l|}{ Chronicity (\% patients) } \\
\hline$\leq 5$ years & $30.7 \%$ & $30.3 \%$ \\
\hline$>5$ and $\leq 10$ years & $31.8 \%$ & $31.9 \%$ \\
\hline$>10$ and $\leq 15$ years & $16.6 \%$ & $16.6 \%$ \\
\hline$>15$ years & $20.8 \%$ & $21.2 \%$ \\
\hline
\end{tabular}

Values are given as mean \pm SEM or as $\%$ of patients. M0, month 0 (inclusion). M6, month 6 (end of study) 
diagnosed as schizophrenia disorder according to the DSM-IV criteria (Table 2). The disease duration was $\leq$ 10 years for $62.5 \%$ of the patients.

\section{Clinical assessment}

Figure 2 shows PANSS core psychotic symptom scores at $\mathrm{M} 0$ and M6. At M0, four mean rating score values were of moderate severity (conceptual disorganization, blunted affect, passive/apathetic social withdrawal, lack of spontaneity and flow of conversation). At M6, all mean rating score were of mild severity.

Table 3 shows that the mean global functioning (GAF rating score) significantly improved $(p<0.001)$ by $5.8 \pm$ 0.45 from M0 (46.4) to M6 (52.2). Figure 3 shows frequency distributions for global functioning scores at M0 and M6. The percentage of high functioning patients (GAF rating scores $>60$ ) increased from $25.2 \%$ at M0 to $42.1 \%$ at M6 $(p<0.0001)$.

Social functioning significantly improved between $\mathrm{M0}$ and M6 (Table 3). Thus, mean social functioning total scores significantly increased by $1.9 \pm 1.0$ from 18.3 to $20.2(p<0.001)$. This resulted from a significant increase $(p<0.001)$ in the rating scores of both social skills and social roles (Table 3 ).

CGI rating scores showed a tendency to decrease throughout the observation period. The average scale score "CGI - Severity" slightly decreased from $4.0 \pm$ 0.032 at M0, to $3.6 \pm 0.032$ at M3 and $3.3 \pm 0.035$ at M6, and the average scale score "CGI - Improvement" evolved from $2.4 \pm 0.022$ at M0 to $2.2 \pm 0.027$ at M6. Consistently, the percentage of patients with CGI severity scores $\geq 5$ (categorized "markedly ill", "severely ill" or "among the most extremely ill patients") decreased from $37.9 \%$ at M0, to $21.3 \%$ at M3 and to $18.7 \%$ at M6.

\section{Other treatments}

The majority of the patients (70.8 \%) had another psychotropic medication, particularly anxiolytics $(57.6 \%$ of

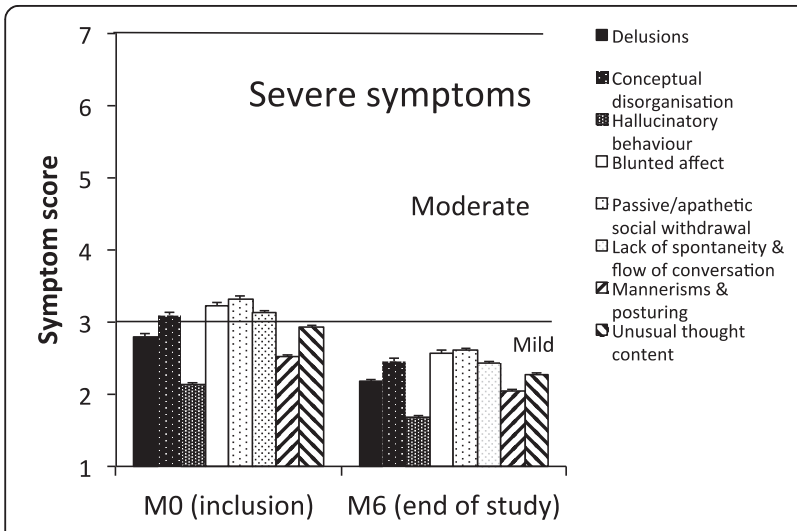

Fig. 2 PANSS core psychotic symptom scores at M0 and M6
Table 3 Evolution of functional performance between M0 and M6

\begin{tabular}{lllll}
\hline & M0 & M6 & M6-M0 & $p$ \\
& $(N=1490)$ & $(N=1354)$ & & \\
\hline GAF rating score $^{a}$ & $46.4 \pm 0.54$ & $52.2 \pm 0.67$ & $5.8 \pm 0.45$ & $<0.001$ \\
$\begin{array}{l}\text { Social functioning } \\
\text { rating score }\end{array}$ & $18.3 \pm 0.11$ & $20.2 \pm 0.12$ & $1.9 \pm 0.10$ & $<0.001$ \\
Social skills & $11.4 \pm 0.06$ & $12.5 \pm 0.07$ & $1.1 \pm 0.07$ & $<0.001$ \\
Social roles & $6.90 \pm 0.05$ & $7.73 \pm 0.06$ & $0.83 \pm 0.05$ & $<0.001$ \\
\hline
\end{tabular}

Values are given as mean \pm SEM. M0, month 0 (inclusion). M6, month 6 (end of study)

${ }^{\text {a }}$ Maximum GAF rating score $=100$

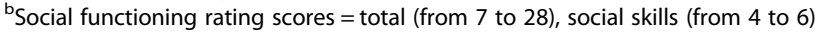
and social roles (from 3 to 12 )

patients), hypnotics (41.8\%) and sedatives (27.0\%). This propensity of patients for other psychotropic medications remained high at M3 (64.6\% of patients) and M6 (62.8\%).

Concerning psychosocial measures, non-specific intervention support was implemented for more than half of the patients $(55.7 \%, 53.5 \%$ and $55.9 \%$ at M0, M3 and M6, respectively).

\section{Remission status according to the PANSS scale (core psychotic symptoms)}

Figure 4 shows that $27.7 \%$ of the patients were in remission at M6, according to the RSWG criteria. This compares well with the $29.9 \%$ of patients with "mild" intensity in core psychotic symptoms at M0, but not with the $58.4 \%$ of patients with "mild" intensity in core psychotic symptoms at M6 (Fig. 4).

At the inclusion visit, patients with a remission of schizophrenia had the following characteristics, as compared with non-remitted patients:

$>$ Better global functioning (GAF rating score $=53.8 \pm$ 1.4 vs. $43.6 \pm 0.54, p<0.001)$

$>$ A better social functioning profile (total score $=21.0$ \pm 0.19 vs. $17.2 \pm 0.12, p<0.001)$

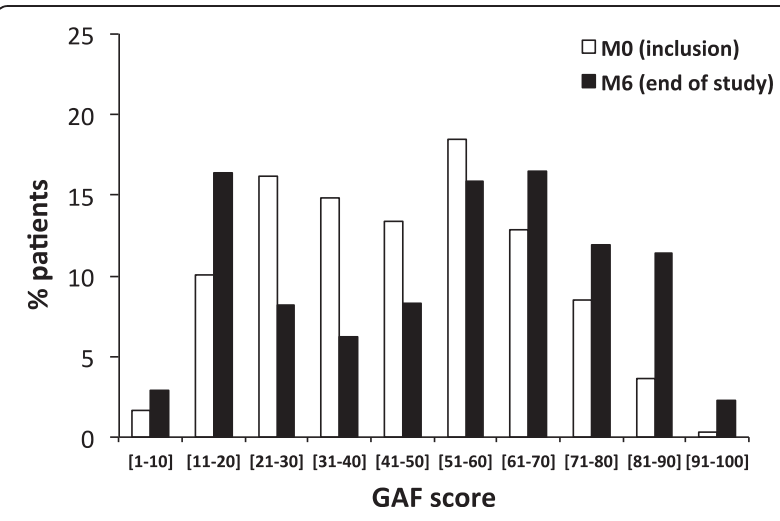

Fig. 3 Frequency distributions for global functioning scores at $\mathrm{MO}$ and $\mathrm{M} 6$ 
$>$ A better CGI severity score $(3.0 \pm 0.052$ vs. $4.4 \pm$ 0.032)

$>$ A better CGI improvement score $(1.9 \pm 0.036$ vs. 2.6 $\pm 0.022)$

\section{Functional performance in remitted schizophrenia patients}

Table 4 shows the functional performance at M6 in patients with remission of schizophrenia. The global functioning rating score was $62.5 \pm 1.5$ (the main objective of the study). This was significantly higher than the mean GAF score in non-remitted patients $(48.3 \pm 0.74, p<0.001)$. Social functioning rating scores were also significantly higher $(p<0.001)$ in remitted patients (Table 4$)$.

\section{Adverse events}

Risperidone LAI was well tolerated. Only 88 of 1491 patients (6 \%) reported at least one AE (anxiety, insomnia, depression, headache). The investigator considered that 69 $\mathrm{AE}$ (18 severe) were related to risperidone LAI treatment.

\section{Discussion}

We analysed a large sample in real-life conditions, with a long follow-up and low attrition rate. After one year of risperidone LAI treatment, $27.7 \%$ of the study's patients were in RSWG-remission. This high remission rate was quantitatively similar to that observed in the StoRMi trial (33\%) [15] and higher than that observed with oral risperidone in the CATIE study $(6.3 \%)$ [9]. This result can be likely explained by non-adherence to long-term oral medication regimes, which is one of the most significant therapeutic issues in the therapy of schizophrenia and related disorders [3].

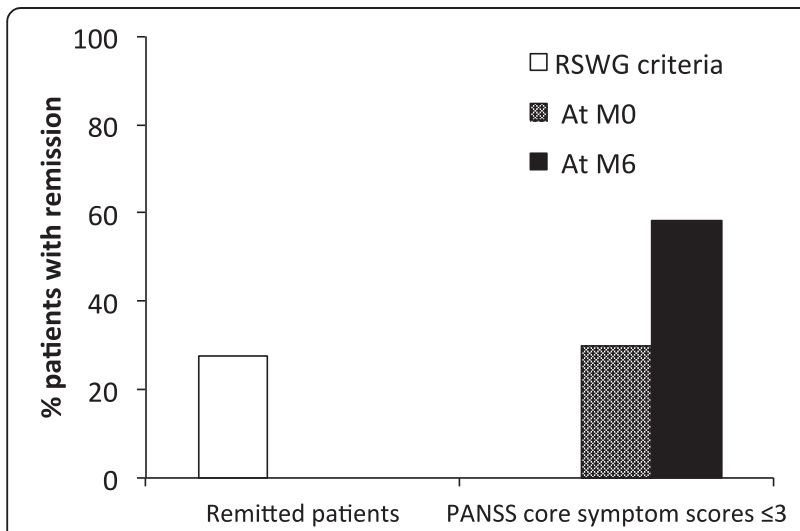

Fig. 4 Remission status according to the PANSS scale (core psychotic symptoms). RSWG criteria include: a score $\leq 3$ for the 8 items of the PANSS scale maintained for at least 6 months. This time criterion could not be evaluated at MO due to the lack of data before inclusion. However, the PANSS score was first evaluated at MO and then 6 months later at M6, so it was possible to evaluate the proportion of patients who met the RSWG criteria at M6
Table 4 Functional performance at M6, in remitted schizophrenic patients (RSWG-criteria)

\begin{tabular}{llll}
\hline & Remitted patients & Non-remitted patients & $p$ \\
\hline $\begin{array}{l}\text { Number of } \\
\text { patients }\end{array}$ & $374(27.7 \%)$ & $976(72.3 \%)$ & \\
$\begin{array}{l}\text { GAF total rating } \\
\text { score }^{\text {a }}\end{array}$ & $62.5 \pm 1.5$ & $48.3 \pm 0.74$ & $<$ \\
$\begin{array}{l}\text { Social functioning } \\
\text { Total rating }\end{array}$ & $21.0 \pm 0.19$ & $17.2 \pm 0.12$ & 0.001 \\
$\begin{array}{l}\text { score } \\
\text { Social skills } \\
\text { rating score }\end{array}$ & $12.8 \pm 0.11$ & $10.8 \pm 0.07$ & $<0.001$ \\
$\begin{array}{l}\text { Social roles } \\
\text { rating score }\end{array}$ & $8.2 \pm 0.10$ & $6.4 \pm 0.06$ & $<0.001$ \\
\hline
\end{tabular}

Values are given as mean \pm SEM or as \% of patients. M6, month 6 (end of study) a Maximum GAF rating score $=100$

${ }^{b}$ Social functioning rating scores $=$ total (from 7 to 28 ), social skills (from 4 to 16) and social roles (from 3 to 12)

Previous studies showed functional improvement under risperidone LAI treatment in patients with stable schizophrenia or schizoaffective disorder [11-14]. On the other hand, the mean GAF rating score in remitted patients (62.5) was higher than the cut-off previously used to identify patients with satisfactory functioning (60) and significantly higher than the mean GAF score in stable, non-remitted patients (48.3). Our study thus clearly shows that further improvement can be obtained in remitted patients (as compared with stable, nonremitted patients).

Achieving functional recovery is a key goal for clinicians treating patients with schizophrenia, but patients with schizophrenia and their families are also concerned with the regain of a patient's ability to act or to give meaning to his or her life (empowerment) and social functioning (managing daily life, social and/or professional skills). It seems, therefore, appropriate to include social functioning as a supplementary criterion of recovery.

Our study suggested that social functioning is also higher in remitted patients as compared with nonremitted patients. However, our scale should be validated in further studies and/or other social functioning scales should be used to confirm this point.

It is important to mention that patients under risperidone LAI continued to improve between their 6 and 12 months of treatment. Thus, the percentage of patients with mild intensity in core psychotic symptoms (PANSS) increased from 29.9 to $58.4 \%$ between 6 and 12 months treatment. In the same period, the percentage of high functioning patients (GAF rating scores $>60$ ) increased from 25.2 to $42.1 \%$. The percentage of patients with CGI severity scores $\geq 5$ (categorized "markedly ill", "severely ill" or "among the most extremely ill patients") decreased from $37.9 \%$ at M0, to $21.3 \%$ at M3 and to $18.7 \%$ at M6. These results illustrate the importance of 
long-acting antipsychotic treatment for ensuring a continuity of symptomatic and functional remission.

Risperidone LAI should be investigated for other recovery aspects of schizophrenia, since patients in RSWGremission have a better cognitive outcome $[19,20]$ and quality of life [21, 22], but may perceive a decreased sense of wellbeing [23]. In addition, Rocca et al. [24] reported that second generation antipsychotic use predicts better social functioning and better executive functions.

\section{Limitations of the study}

The results apply to chronic patients, two-thirds of them with over 5 years of the disorder. The scope of our study does not allow for a certain conclusion about symptom improvement being due to risperidone specifically, since there is no information about other treatments. Furthermore, the choice of a GAF of 60 as cut-off for functional remission was frequently used, but it is arbitrary. Finally, the Social Functioning in Schizophrenia is an ad hoc scale. Such limitations should be taken into consideration by future studies.

\section{Conclusions}

Our results clearly show that after one year of treatment with risperidone LAI, RSWG-remitted patients have a high level of global functioning, which is significantly higher than in stable, non-remitted patients. Social functioning was also higher in remitted patients as compared with stable, nonremitted patients. This latter should be confirmed in further studies using validated social functioning scales.

\section{Availability of data and materials}

Data and materials can be requested to Dr. Ricardo P. Garay (ricardo.garay@orange.fr).

\begin{abstract}
Abbreviations
AE: Adverse Events; CCTIRS: Comité Consultatif pour le Traitement de l'Information en matière de Recherche dans le domaine de la Santé (Advisory Committee for the Evaluation of Information in the field of Health Research); CEGEDIM: Centre de gestion et de Documentation de l'Information Médicale (Management and documentation centre of medical information); CGI: Clinical Global Impression; CGI-S: Clinical Global Impression - Severity scale; CNIL: Commission Nationale de l'Informatique et des Libertés (National Committee of informatics and Freedom); EVeREST: EValuation of functioning in REmission after Symptomatic Treatment; GAF: Global Assessment of Functioning; LAl: Long-Acting Injection; PANSS: Positive And Negative Symptom Scale; RSWG: Remission in Schizophrenia Working Group; StoRMi: Switch to Risperidone Microspheres; SEM: Standard Error of the Mean
\end{abstract}

\section{Competing interests}

Elisabeth Giraud Baro has received consultant fees or honoraria on various projects in the field of psychiatry from Astra Zeneca, Janssen, Lundbeck, Roche, and Servier. During the past five years, Daniel Dassa has received consultant fees or honoraria on various projects in the field of psychiatry from Astra-Zeneca, BMS, Eisai, Janssen, Lilly, Lundbeck, Otsuka, Roche, Servier, and Takeda. Florent de Vathaire has received consultant fees or honoraria on various projects in the field of psychiatry from C2R. Ricardo P. Garay is a member of a non-profit association for therapeutic innovation (Craven, Villemoisson-sur-Orge, France). Joelle Obeid is an employee of Janssen-Cilag France. The study was sponsored by Janssen Cilag (Issy les Moulineaux, France).

\section{Authors' contribution}

EGB and DD were the main investigators of the study; they contributed to the design of the study and the interpretation of data, and they revised the manuscript. FDV contributed to the design of the study and performed the analysis. RPG drafted and revised the manuscript and contributed to the interpretation of data. JO contributed to the interpretation of data and revised the manuscript. All authors read and approved the final manuscript.

\section{Acknowledgements}

We thank Janssen-Cilag (Issy-Les-Moulineaux, France) for sponsoring this study and Craven (Villemoisson-sur-Orge, France) for providing medical writing services on behalf of Janssen-Cilag France.

\section{Author details}

${ }^{1}$ Hospital Center of Saint-Egrève, Saint-Egrève, France. ${ }^{2} \mathrm{CHU}$ La Timone, Marseilles, France. ${ }^{3}$ INSERM U1018, Institute Gustave Roussy, Villejuif, France. ${ }^{4}$ Craven, Villemoisson-sur-Orge, France. ${ }^{5}$ Janssen-Cilag France, Issy Les Moulineaux, France.

Received: 7 July 2015 Accepted: 8 January 2016

Published online: 15 January 2016

\section{References}

1. Cañas F, Möller HS. Long-acting atypical injectable antipsychotics in the treatment of schizophrenia: safety and tolerability review. Expert Opin Drug Saf. 2010;9:683-97.

2. Fleischhacker WW. Second-generation antipsychotic long-acting injections: systematic review. Br J Psychiatry. 2009;52 Suppl:S29-36.

3. Rainer MK. Risperidone long-acting injection: a review of its long term safety and efficacy. Neuropsychiatr Dis Treat. 2008;4:919-27.

4. Andreasen NC, Carpenter WTJ, Kane JM, Lasser RA, Marder SR, Weinberger DR. Remission in schizophrenia: proposed criteria and rationale for consensus. Am J Psychiatry. 2005;162:441-9.

5. Lasser RA, Bossie CA, Gharabawi GM, Kane JM. Remission in schizophrenia: Results from a 1-year study of long-acting risperidone injection. Schizophrenia Res. 2005;77:215-27.

6. Kissling W, Heres S, Lloyd K, Sacchetti E, Bouhours P, Medori R, et al. Direct transition to long-acting risperidone - analysis of long-term efficacy. J Psychopharmacol. 2005;19:15-21.

7. Llorca PM, Sacchetti E, Lloyd K, Kissling W, Medori R. Long-term remission in schizophrenia and related psychoses with long-acting risperidone: results obtained in an open-label study with an observation period of 18 months. Intl J Clin Pharmacol Ther. 2008:46:14-22.

8. Möller H-J, Llorca P-M, Sacchetti E, Martin SD, Medori R, Parellada E, et al. Efficacy and safety of direct transition to risperidone long-acting injectable in patients treated with various antipsychotic therapies. Intl Clin Psychopharmacol. 2005;20:121-30.

9. Levine SZ, Rabinowitz J, Ascher-Svanum H, Faries DE, Lawson AH. Extent of attaining and maintaining symptom remission by antipsychotic medication in the treatment of chronic schizophrenia: Evidence from the CATIE study. Schizophrenia Res. 2011;133:42-6.

10. Leucht S. Measurements of response, remission, and recovery in schizophrenia and examples for their clinical application. J Clin Psychiatry. 2014;75 Suppl 1:8-14.

11. Rosa F, Schreiner A, Thomas P, Sherif T. Switching patients with stable schizophrenia or schizoaffective disorder from olanzapine to risperidone long-acting injectable. Clin Drug Invest. 2012;32:267-79.

12. Lloyd K, Latif MA, Simpson S, Shrestha KL. Switching stable patients with schizophrenia from depot and oral antipsychotics to long-acting injectable risperidone: efficacy, quality of life and functional outcome. Human Psychopharmacol Clin Expl. 2010;25:243-52.

13. Rouillon F, Eriksson L, Burba B, Raboch J, Kaprinis G, Schreiner A. Functional recovery results from the risperidone long-acting injectable versus quetiapine relapse prevention trial (ConstaTRE). Acta Neuropsychiatrica. 2013;25:297-306

14. Llorca PM, Bouhours P, Moreau-Mallet V. Improved symptom control, functioning and satisfaction in French patients treated with long-acting injectable risperidone. Encephale. 2008;34:170-8.

15. Lambert M, De Marinis T, Pfeil J, Naber D, Schreiner A. Establishing remission and good clinical functioning in schizophrenia: Predictors of best outcome with long-term risperidone long-acting injectable treatment. Eur Psychiatry. 2010;25:220-9. 
16. Bonaïti-Pellié C, Arveux P, Billette de Villemeur A, Dantchev N, Elbaz A, Fabre-Guillevin $\mathrm{E}$, et al. Traitement de l'information en matière de recherche dans le domaine de la santé. Med Sci (Paris). 2009;25:93-8.

17. DREES. Direction de la Recherche, des études, de l'évaluation et des statistiques. http://www.epsilon.insee.fr/jspui/bitstream/1/13669/1/ seriestat88.pdf. Sicart P. Les médecins, estimations au 1er janvier 2005. Série Statistiques 2005; n88. Last Accessed: 1 July 2015.

18. Martinez-Aran A, Vieta E, Torrent C, Sanchez-Moreno J, Goikolea JM, Salamero M, et al. Functional outcome in bipolar disorder: the role of clinical and cognitive factors. Bipolar Disorders. 2007;9:103-13.

19. Braw Y, Sitman R, Cohen M, Berger U, Lev-Ran S, Segev A, et al. Remission of positive symptoms according to the "remission in Schizophrenia Working Group" criteria: A longitudinal study of cognitive functioning. Eur Psychiatry. 2013;28:282-7

20. Pinna F, Bosia M, Cavallaro R, Carpiniello B. Consensus five factor PANSS for evaluation of clinical remission: effects on functioning and cognitive performances. Schizophrenia Res: Cognition. 2014;1:187-92.

21. Chang WC, Chan TCW, Chen ESM, Hui CLM, Wong GHY, Chan SKW, et al. The concurrent and predictive validity of symptomatic remission criteria in first-episode schizophrenia. Schizophrenia Res. 2013;143:107-15.

22. Heering $H$, Janssens $M$, Boyette $L$, van Haren NEM. Remission criteria and functional outcome in schizophrenia patients. A longitudinal study. Schizophrenia Res. 2014;153 Suppl 1:S166-7.

23. Pinna F, Deriu L, Lepori T, Maccioni R, Milia P, Sarritzu E, et al. Is it true remission? A study of remitted patients affected by schizophrenia and schizoaffective disorders. Psychiatry Res. 2013;210:739-44.

24. Rocca P, Montemagni C, Castagna F, Giugiario M, Scalese M, Bogetto F. Relative contribution of antipsychotics, negative symptoms and executive functions to social functioning in stable schizophrenia. Progress NeuroPsychopharmacol Biological Psychiatry. 2009;33:373-9.

\section{Submit your next manuscript to BioMed Central and we will help you at every step:}

- We accept pre-submission inquiries

- Our selector tool helps you to find the most relevant journal

- We provide round the clock customer support

- Convenient online submission

- Thorough peer review

- Inclusion in PubMed and all major indexing services

- Maximum visibility for your research

Submit your manuscript at www.biomedcentral.com/submit

) Biomed Central 